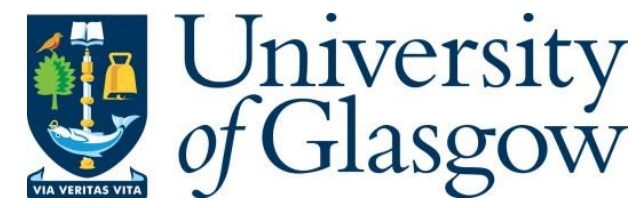

Welch, V., Turner-Halliday, F., Watson, N., Wilson, P., Fitzpatrick, B., Cotmore, R. and Minnis, H. (2017) Randomisation before consent: avoiding delay to time-critical intervention and ensuring informed consent.

International Journal of Social Research Methodology, 20(4), pp. 357-371. (doi:10.1080/13645579.2016.1176751)

This is the author's final accepted version.

There may be differences between this version and the published version. You are advised to consult the publisher's version if you wish to cite from it.

http://eprints.gla.ac.uk/120082/

Deposited on: 13 June 2016

Enlighten - Research publications by members of the University of Glasgow http://eprints.gla.ac.uk 


\section{Randomisation before consent: Avoiding delay to time-critical intervention and ensuring informed consent}

Vicki Welch ${ }^{1}$, Fiona Turner-Halliday ${ }^{2}$, Nicholas Watson ${ }^{2}$, Phil Wilson ${ }^{3}$, Bridie Fitzpatrick ${ }^{4}$, Richard Cotmore $^{5}$ and Helen Minnis ${ }^{2}$

07/04/2016 accepted for publication in:

The International Journal of Social Research Methodology. 1364-5579 (Print), 1464-5300 (Online). http://www.tandfonline.com/toc/tsrm20/current

\footnotetext{
${ }^{1}$ Corresponding author. Vicki.welch@strath.ac.uk. Centre for Excellence for Looked After Children in Scotland, University of Strathclyde.

${ }^{2}$ Institute of Health and Wellbeing, University of Glasgow.

${ }^{3}$ Centre for Rural Health, University of Aberdeen.

${ }^{4}$ College of Medical, Veterinary and Life Sciences, University of Glasgow.

${ }^{5}$ NSPCC, London.
} 


\title{
Randomisation before consent: Avoiding delay to time-critical intervention and ensuring informed consent
}

\begin{abstract}
Obtaining informed consent can be challenging in stressful and urgent circumstances. One example is when potential participants have recently had their child removed into care; intervention is urgent and mandatory whereas participation in associated research is voluntary. Using a nested qualitative study, we examined experiences of consent processes in a randomised controlled trial (RCT) of a family assessment and intervention service for maltreated young children. Some potential participants found it difficult to use information; some believed consenting might influence the return of their child. In response to these ethical challenges, we propose reversing the typical process of securing consent, so that randomisation to an intervention occurs before inviting potential participants to consider the trial. This will avoid delays, delineate research from intervention, and make it easier to consider information. We suggest that this innovation could be useful in trials across service areas that incorporate urgent and complex interventions.
\end{abstract}

\section{Introduction and literature}

Accepted standards of ethical research required that when invited to take part in research, potential participants should have capacity to consider the implications of participation, they should have access to full and accurate information about the research, and they should not experience coercion. However, achieving informed consent can be difficult, particularly where the research takes place in a context of challenging or stressful circumstances. In this paper, we discuss such a context, describing issues related to the informed consent of parents who had recently had their child placed into foster care.

When state authorities have mandatorily removed a child on the grounds of parental maltreatment, urgent action is needed. Typically this includes a period of complex assessment of the child and family's needs and capacities. The findings of these assessments inform decisions about the longer-term care of the child. It is important for the wellbeing of the child and family that decisions should occur promptly, as soon as sufficient, appropriate, accurate information is available.

Consider then, would a trial of assessment or decision-making processes be possible? The intervention and assessment are not just urgent, they are mandatory; by contrast, participation 
in any trial would have to be voluntary, and would require careful processes to secure informed consent.

In this paper, we describe the findings of a qualitative study that was nested within a randomised controlled trial (RCT) comparing two early assessment interventions for babies and young children recently removed from their families to foster care. Each of these interventions aimed to support children and families whilst gathering robust information to enable appropriate decision-making.

We explored parents and recruiters' experiences of the consent process and found that even with support, some parents found it hard to use the information given. Furthermore, in a context where their family was subject to compulsory intervention, some did not understand, or believe, that involvement in the trial was voluntary, instead believing that by providing consent they could influence decisions made about their child. In the trial, randomisation to a service, and hence the start of assessments or intervention, occurred after consent processes. However, we also found that recruitment to the trial was sometimes difficult and time consuming and resulted in delays for the child and family.

The challenges identified in the study prompted us to reconsider trial protocols. We propose reversing the typical process of securing consent, so that randomisation to an intervention occurs before inviting participants to consider participation in the trial. This will avoid delays and allow potential participants to consider participation when they are able to use information and understand that their decisions about participation will not influence decisions about their child's future. Before describing the trial and the nested study, we address literature related to securing informed consent to trial participation and literature concerning the context of intervention for families in this study. We then present the findings of the qualitative study and move on to discuss the alternate trial protocol that we feel is ethically preferable. We suggest that this innovation could be useful in trials across a range of service areas that incorporate urgent and complex interventions.

\section{Literature regarding informed consent and the context of the trial}

Research involving human participants across a number of social, sociological, psychological and medical spheres is regulated by institutional and organisational research ethics boards, professional codes, and, in some jurisdictions, by legislation (BPS, 2014; BSA, 2002; SRA, 2003; Tu et al., 2004). Underpinning this regulation are principles and values established in the World Medical Association Declaration of Helsinki (WMA, 2013) and the earlier 
Nuremberg Code (1947). Whilst these were originally developed as guidelines to govern medical research, they have now been incorporated into codes and regulations employed by various organisations conducting research with human subjects.

A core principle is that individuals should be free to make their own decisions according to their own judgements about whether to participate in research, this underpins the need to secure informed consent (Corrigan, 2003; O'Neill, 2003). It has been suggested that dominant technical-rational and bioethical frameworks can view the informed consent process in a simplistic way devoid of social context or recognition of individuals' differing values, beliefs, and ways of thinking (Corrigan, 2003). However, research is inherently complex and ethical principles cannot guide action in a deterministic way; each ethical judgement is uniquely situated and, in any set of circumstances, different principles may seem to indicate different courses of action. (Hammersley, 2014).

Much of the literature focused on informed consent is derived from trials of healthcare interventions; less is known about informed consent in social research, particularly in respect of vulnerable groups such as children (Alderson \& Morrow, 2004; Parsons, Abbott, McKnight, \& Davies, 2015; Wiles, Crow, Charles, \& Heath, 2007) or with particular methodologies (Renold, Holland, Ross, \& Hillman, 2008).

Informed consent is predicated on; the capacity of the decision maker, provision of all necessary information presented in a way that is sensitive to their needs, and an absence of coercion or deception (O'Neill, 2003). In the context of research, this places a responsibility on investigators to provide potential participants full and accurate information and to ensure that their study processes promote individual participants' understanding and ability to choose freely (Behrendt, Gölz, Roesler, Bertz, \& Wünsch, 2011). Researchers must take extra care when potential participants are subjected to compulsion in other aspects of their lives (Edens, Epstein, Stiles, \& Poythress, 2011; Wolbransky, Goldstein, Giallella, \& Heilbrun, 2013).

Researchers also need to ensure that the data they collect are of high quality, their findings are valid and that they deploy scarce resources effectively, to do this, they need to ensure sufficient recruitment to their trials (Crow, Wiles, Heath, \& Charles, 2006). This can create a tension between ensuring that consent is informed and voluntary whilst promoting maximum participation (Wade, Donovan, Athene Lane, Neal, \& Hamdy, 2009). However, participation 
rates can be higher when consent processes succeed in providing good quality information and support (Flory \& Emanuel, 2004).

Obtaining consent that is fully informed and voluntary can be resource-intensive and, in some cases, problematic (Behrendt et al., 2011). There can also be various circumstances where seeking consent is impractical or impossible, such as in the delivery of emergency medical intervention (Appelbaum, Roth, \& Lidz, 1982; Edwards et al., 2002; Mason \& Allmark, 2000), or in the case of using stored data or materials after participants have left an institution (Tu et al., 2004). Equally, it has been suggested that in some circumstances the act of seeking consent risks harm, for example by creating misconceptions, raising unmet expectations or producing further anxiety in already stressful situations (Allmark, 1999; Carpenter et al., 2000; Joffe, Cook, Cleary, Clark, \& Weeks, 2001).

Many studies have found that participants do not fully understand the information they receive during consent processes, particularly information about the details of the study (Behrendt et al., 2011; Flory \& Emanuel, 2004). Researchers have tried a number of methods to improve potential participants' understanding of information, including the use of enhanced written information, multi-media information, and detailed discussions and questioning (Flory \& Emanuel, 2004; Joffe et al., 2001; Nishimura et al., 2013). In their review of studies of interventions to improve understanding during consent processes, Flory and Emanuel (2004) found the most promising results were obtained by the provision of extended discussions in a one-to-one setting.

There is evidence to suggest that as well as the content of information, the structures, settings and manner in which information is given and participation invited all impact on potential participants' understanding and willingness to raise queries or concerns (Fisher, 2013; Flory \& Emanuel, 2004; Wade et al., 2009).

Equally the timing of information is also important; for example, parents of babies with perinatal asphyxia who were asked to consent to an RCT of an innovative intervention were found to be more able to understand information at various follow-up points (Allmark \& Mason, 2006). Similarly, a wider study of parents of new born babies being recruited to a range of trials, found their competence was lowest in emergency situations (Mason \& Allmark, 2000). 
Smyth, Jacoby, and Elbourne (2012) explored views of participants in a RCT of a drug for the life-threatening condition pre-eclampsia. They identified issues related to the timing of information and consent, the quality of consent materials and professional influences on participation. They suggest that despite the researchers' best efforts, some participants had not fully comprehended what was being asked of them at the time of giving consent, due to the stressful circumstances in which they were informed about the study (Smyth et al., 2012)

Individual and demographic characteristics of potential participants are important, in particular, levels of education may affect ability to use information (Flory \& Emanuel, 2004; Joffe et al., 2001). However, there is also evidence that consent processes can be adapted to meet the needs of vulnerable groups and individuals (Carpenter et al., 2000; David, Edwards, \& Alldred, 2001). As well as responding to individual need, some authors suggest that participants' autonomy could be promoted by enabling them to indicate what type of information and what level of detail they wish to receive (O'Neill, 2003).

Other potentially helpful approaches where there is doubt about whether participants were able to understand or use the information that was provided at the start of the trial include the idea of continuous or contingent consent, where study information and consent is revisited throughout the research and intervention (Allmark \& Mason, 2006; Renold et al., 2008). Equally, researchers can enable participants to rescind consent and opt out of a study at a later time (O'Neill, 2003; Renold et al., 2008).

Having reviewed literature related to informed consent, we now briefly address literature that provides important context for our trial.

The state removes children from the care of their birth families when there are concerns about significant harm caused by maltreatment (abuse or neglect) and a risk of further maltreatment that cannot be resolved without their removal. In Scotland ${ }^{6}$, as in the rest of UK, young children are typically placed into foster care pending assessments and formal decisions about their future living arrangements. Potentially this may result in the permanent removal of the child from the care of their parents. Many families experience an extended period of separation and uncertainty during this process as time elapses without decisions being made (Sinclair, Baker, Lee, \& Gibbs, 2007; Thoburn \& Courtney, 2011). Care systems in the UK

\footnotetext{
${ }^{6}$ Legal systems related to childcare differ in different parts of the UK; the initial phase of this trial took place under Scottish law.
} 
are characterised by instability; many children experience placement moves whilst separated from their parents or are sent home to come back into care later (Farmer, 2014; Minnis, Bryce, Phin, \& Wilson, 2010; Munro \& Hardy, 2006).

Rapidly and definitively securing a nurturing and stable home, either with the child's birth family or in an alternative placement helps to reduce the impact of earlier abuse or neglect (Carnochan, Moore, \& Austin, 2013; Dozier, Peloso, Lewis, Laurenceau, \& Levine, 2008; Lieberman, Van Horn, \& Ippen, 2005; Potter \& Klein-Rothschild, 2002; Schofield, Thoburn, Howell, \& Dickens, 2007; Thoburn \& Courtney, 2011; Zeanah et al., 2001). Conversely, instability and delay in finding a permanent place is detrimental to children's development and wellbeing (Zeanah, Gunnar, McCall, Kreppner, \& Fox, 2011).

Child protection is an under-researched area; there is both a lack of evidence about the ethics of research and a lack of robust knowledge to underpin intervention (Douglas \& Serino, 2013; Stevens, Liabo, \& Roberts, 2007; Williams \& Sherr, 2013). In a review of literature related to social care practitioners' priorities, Stevens et al. (2007) found the most frequently cited gaps in evidence involved the effectiveness of interventions for child protection, parenting and family support. However, definitive research in these areas has proved difficult because of the inherent contextual complexities (Dombo \& Bass, 2014; Zeira et al., 2008), and individual-level issues such as the relationship between the worker and client (Graybeal, 2007). To transcend the impact of these factors, and assess the efficacy of complex interventions, greater use of RCTs has been advocated (Roberts, Petticrew, Liabo, \& Macintyre, 2012). However, RCTs of complex interventions in child protection and related fields remain rare (see for example Newman \& Roberts, 1997; Soydan, 2008; Webber, 2014). There are a number of ethical challenges for researchers conducting RCTs in complex circumstances, not least the issue of securing informed consent from sufficient numbers of participants.

\section{The trial}

The evidence base for family assessment and early intervention for children removed from their families is weak and practice varies (Broadhurst et al., 2010; Horwath, 2005; Regehr, Bogo, Shlonsky, \& LeBlanc, 2010). One programme from New Orleans for maltreated infants (Zeanah et al., 2001) aims to intervene with the birth family to enable the child to return home, and where this is not possible, to recommend a secure and nurturing home through adoption. It involves detailed family assessment followed by a period of intervention 
delivered by a multi-agency team including psychologists and social workers. To test the applicability of this type of intervention in the UK context, a feasibility randomised controlled trial $\left(\mathrm{BeST}^{7}{ }^{7}\right.$ ) was set up to compare the New Orleans model, run by the Glasgow Infant and Family Team (GIFT) with an enhanced 'services as usual' model in Glasgow provided by the Family Assessment and Contact Service (FACS) (Pritchett et al., 2013). Importantly, there was not enough of either service to meet all needs in Glasgow, and there was equipoise in that we did not know or suspect either service to be superior to the other. The West of Scotland Research Ethics Committee and the NHS Greater Glasgow and Clyde Research and Development office approved the trial.

\section{The trial recruitment process}

In this trial, as in most RCTs, consent to participate was sought prior to random allocation to a service. Social workers for all families in Glasgow with a child aged 6 to 60 months beginning a period of foster care due to suspected maltreatment asked parents for their permission for the study's recruitment officer to contact them to discuss potential participation in the trial. To facilitate appropriate and sensitive consent processes, study recruiters were qualified social workers experienced in child protection work; however, the University of Glasgow employed them as study recruiters, not in a social work role.

On receiving permission, recruiters made contact with the parent(s) to arrange a meeting, usually at the family home or a convenient service location. Recruiters provided information in various formats including written leaflets, digital video discs (DVD) and one-to-one discussions, in person and over the telephone. Where necessary, recruiters made repeat visits or calls; typically, one or two visits were sufficient, the maximum number of contacts required was four.

The families of consenting parents were randomly allocated to one arm of the study and nonconsenting families were routed to FACS as 'services as usual', see Figure 1.

\section{$<$ Fig 1 about here $>$}

Between December 2011 and February 2014, social workers referred 177 children to the trial, of these, 45 were ineligible (e.g. child was outside the 6-60 month age range or the episode of care was not associated with maltreatment. Of the remaining 132 eligible children, 99 were

\footnotetext{
${ }^{7}$ BeST ${ }^{?}$ Services Trial: See http://www.clinicaltrials.gov/ct2/show/NCT01485510?term=gift\&rank=12
} 
consented to be part of the trial (75\%) and $18(14 \%)$ declined consent. Ten (8\%) were 'lost to the study', either because a placement decision was made before participation in the trial was discussed, or because it proved impossible to discuss consent with the family within 12 weeks of the child entering care. At the time of reporting, five (4\%) were undergoing recruitment processes. Initially we were concerned at the high consent rate for the trial; particularly given this group might belong to a population that researchers typically find hard to recruit. In the next section, we describe the methods we adopted to determine people's reasons for entering the trial.

\section{The nested qualitative study}

We adopted a nested qualitative study to examine the experiences of various individuals in relation to their involvement with the trial. Two researchers who were independent of the recruitment process conducted semi-structured interviews with a convenience sample of seven families who had consented to be part of the trial and with two recruiters involved in consenting families in the study. The aim of these interviews was to explore the parents' experiences of and reflections on the recruitment process. We are not able to say whether these parents were representative of all those involved in the trial, however, this sample included single parents, couples, and a parent accompanied by a member of their wider family. The interviews took place a few weeks after the parent(s) had consented to be part of the trial; for some, this was at a point when the relevant service was beginning to contact them or initiate intervention. Most interviews took place face-to-face in parents' homes; however, one participant preferred a telephone interview. Interviews typically took between 30 and 90 minutes. In addition, a researcher conducted semi-structured interviews with the two recruiters for the trial; these took up to 90 minutes.

With permission, all interviews were audio recorded and transcribed in full. The transcripts were imported into NVivo to facilitate a process of thematic analysis (Braun \& Clarke, 2006). Initial themes were discussed and refined by three researchers and the resulting themes were used to construct a number of framework matrices against which all the data were further coded (Ritchie \& Spencer, 1994). We present our findings illustrated by quotations attributed to the generic terms 'Father', 'Mother' or 'Recruiter'.

\section{Study limitations}

An important limitation of this study was the fact that the qualitative element described here was an intrinsic part of the overall trial; we were unable to interview families if they had not 
consented to be part of the trial itself. Our analyses were therefore based on the perspectives of families who consented to take part in the trial; it is possible that families who did not consent (i.e. 14\%), may have provided different perspectives and insights. A further limitation might be that the sample size was relatively small (seven families); however, different types of family were included, the data collected were highly detailed, and themes were consistently evident across the entire data set. We were also able to triangulate our findings by recourse to the views of the recruiters as well as parents; this provided some breadth as well as depth.

\section{Findings}

In this section, we first address parents' capacity at the time of the consent process followed by their experiences of the consent process and the extent to which they were able to understand the information provided. Finally, we look at various factors that influenced their decisions.

\section{The impact of having a child removed}

The removal of their child placed parents under a great deal of stress. In addition to the problems and circumstances that had brought them to this point, families were now dealing with the pain of separation and the fear that their child would not be returned. In addition, parents faced a raft of processes that demanded their time and energy, including bureaucratic, legal, and logistical issues as parents tried to have their child returned to them and manage visits or other contacts with their child. All parents characterised their situation as difficult, out of their control, confused and emotionally challenging:

Every day for [Child] to be out of the house is an agony for us, every day is an agony for us, [Mother's name] has had a lot, you know, a lot of things have happened and she has had a lot of difficulties because of this, and so have I. [Child] is the most important thing in either of our lives...

(Father)

All the families felt the decision to remove their child was wrong; some because they felt the social worker was biased or even malicious and that they were being falsely charged. Parents felt desperate to secure the return of their child and this often preoccupied their thoughts, dominating other aspects of their life:

My mind's been on other things just trying to get the weans [children] back and things like that, so I think it [consent process] has just been too much to take on board just now really. 
(Mother)

The trial recruiters were acutely aware of the pressures that parents faced and reported making strenuous efforts to ensure that the recruitment processes met parents' needs:

... something I really pick up that families are not listening and I find it actually quite difficult to keep going in the face of these people just... they are stressed, sometimes they are angry and those are the ones I like to go back to.

(Recruiter)

\section{Experiences of the consent process}

The trial was designed to ensure consent was fully informed; the protocols enabled recruiters to spend time with families, and, where necessary, provide repeat visits and further opportunities to discuss concerns or queries. Parents welcomed this, and saw the recruiters as approachable and informative. Tactics such as providing information in a variety of different formats had some success:

I was sort of trying to read about it, but it only told you it was like tossing a coin and stuff and I was like, right well what way do I go, so we put the DVD in and it sort of explained a bit more and it showed you a mother with a child, so it sort of showed you rather than reading.

(Mother)

However, despite these efforts, some parents reported finding the information, or elements of it, difficult to understand. For example, some did not understand or accept the concept that the services were equally likely to be beneficial, feeling that a service worthy of being trialled in this way would necessarily be superior. Similarly, some found it difficult to understand that the trial was independent of the services and the systems that had removed their child or that the researchers had no influence on the outcome for their child. Some parents also struggled to understand how randomisation would work in this context or grasp that even if they opted out of the study, they would still receive an intervention:

There is going to be an assessment anyway, which I didn't know about until yesterday right, but if there is going to be this assessment, then why not take part in the study as well...

(Mother)

\section{How informed was the consent?}

The interviews for the qualitative study took place some weeks after parents had consented to the trial. It was clear that some parents had not fully understood the information provided at the outset and some parents took this opportunity to ask further questions about the trial. On 
listening to further explanations, these parents reported better understanding, and importantly none wished to withdraw from the trial.

Parents sometimes attributed their lack of retention or understanding of information to a number of individual barriers such as learning and literacy difficulties, the stress of losing a child or the number and range of services that were involved in their lives;

On a Tuesday we have six different organisations that come out...one is leaving and the other one is pressing the buzzer, and it is like, two minutes peace.

(Mother)

Some also cited the influence of other difficulties including poor mental health, substance use, family problems, and lack of current information or worry about their child. Some parents suggested that various factors came together to make it difficult to attend fully to the information:

... until such time as we find out... at least find out what's happening with [child], never mind getting returned, it is difficult for us to give things the attention that they maybe should get.

(Father)

\section{Reasons for participation}

Their strong desire to secure the rapid return of their child meant that some parents chose not to scrutinise the trial information, ask for more information, or seek further clarification for fear of introducing a further delay:

Mother: $\quad$ It is just, it is all confusing, wouldn't say confusing, just want to get progress made.

Father: $\quad$ It is confusing and all, because we really don't know what it is.

Mother: $\quad$ I thought BeST was the actual company [service], I didn't know it was two companies [services].

Father: $\quad$ We would rather not admit that we don't know anything about it and just go along with it, than admit it...

Mother: $\quad$ And get pure stuck and confused half way into it.

Father: $\quad$ And start back at the start.

The recruiters were aware of this issue and reported that they often advised parents to take more time and reflect on the process:

... this man said 'oh no, no, I will sign now, I'll sign now' and I said 'look I really would prefer that you would just think about this, you have got the DVD now, you can 
talk to your family, you know, people can ask you questions'. But he said 'no, no I want to do it now'

(Recruiter)

When asked why they had consented to take part in the trial a few parents also cited altruistic reasons for taking part such as suggesting that the trial may potentially help other families.

Others seemed more concerned with their own situation. Several parents suggested they took part because it was a potential opportunity to receive the new, and in their eyes, better service. Others agreed to take part because they felt they might gain more information about their child:

Well [social worker] said to me 'would I take part in it, it explains everything about how my wean [child] has been alright?'. And I said 'yes' so I know my wean is fine.

(Mother)

These parents often referred to their contacts with social workers and were keen to portray themselves as someone willing to make the necessary changes to secure their child's return:

... and we've even said that to the social work, that we are willing to do anything as long as I get the wean [child] back. We don't care what they make us do, we will do it anyway, just so we get to have him back. So, whatever they want.

(Mother)

Some parents reported that friends, family and others had advised them to be compliant and refrain from challenging social workers:

It comes directly from every advisor that we have got, both sets of solicitors [and] the children's reporter have said to us that regardless [...] of what you prove in court [...] or anything at all like that, the social work department have a very strong influence on any decision made by anyone, and the best way to deal with them is to do as you are to, literally do as you are told.

(Father)

Despite assurances from recruiters that opting in or out of the trial would not influence the speed or likelihood of their child's return, some parents believed they could use the consent process as a further opportunity to demonstrate their compliance and hence help to secure their child's return:

Interviewer: What made you decide to take part in it?

Mother: $\quad$ Basically to show [social worker] that I am willing; doing everything to get him back. 


\section{Discussion}

Trial-related delays in the child receiving a service or to decisions about the child's permanent placement are unacceptable as they potentially harm the child. In addition, delays may prevent researchers from conducting similar trials in jurisdictions that prescribe timeframes for decision-making. The consent process for this trial was unusual in that parents were asked to give consent on behalf of children who were removed from their care. Our data point to a number of challenges faced by recruiters and families who often had chaotic lives. It frequently took several weeks to complete the informed consent process. This was a particular concern since randomisation to a service did not happen until this process was complete, hence, this aspect of the study contributed to delays in the initiation of intervention and assessment, and ultimately to decision-making about the child's future that impact on the child's wellbeing.

Participant understanding of information is often poor, and despite best efforts incorporating a number of measures to enhance understanding (Flory \& Emanuel, 2004). Other research has shown that a range of factors may impact on capacity to give informed consent, including immaturity, illness, learning difficulties, medication, intoxication and stress (Carpenter et al., 2000; David et al., 2001; Edwards et al., 2002; Flewitt, 2005; Reid, Ryan, \& Enderby, 2001). Some parents in this study seemed to have had reduced capacity to make decisions about trial consents. It seems their emotions are raw and stresses are high as they are grappling with various bureaucratic, legal, and logistical processes related to their child's removal and their feelings of control are low. However, there was also some indication that at the time of follow-up interviews they were more able to understand issues related to the trial. Asking parents to consider consent at a time when they are distressed may itself be unethical (Allmark \& Mason, 2006). Whilst many of the stresses faced by these families will undoubtedly continue whilst parents and their child remain apart, it seems that a few weeks after the initial separation, some parents were more able to fully consider participation and make an informed choice. In this respect, these parents may not be unique; other difficult but passing situations where research participants' capacity may be compromised could include periods of illnesses, during legal proceedings, at the start of incarceration, periods of high demand (at home or work), following recent bereavements, etc.

An additional complication of this context was that parents understood they were required to engage with the services performing relevant assessments and interventions and that failure 
to engage would increase the likelihood of the permanent removal of the child. Against this coercive backdrop, recruiters had to inform parents about voluntary participation in a trial. Not all parents in the trial were able to understand the information provided and remained confused about their engagement in an intervention that was effectively compulsory, and their decision to take part in a trial that was voluntary. Also despite assurances otherwise, some parents felt that their decision would affect the likelihood and timing of their child's return home, which is highly important for parents in this situation (Burgess, 2007; O'Neill, 2003). Thus, these findings suggest that parents who were subjected to compulsory measures may have perceived participation in the trial as somewhat coercive, feeling that participation would increase the likelihood that their child would be quickly returned to them.

Wider research highlights other groups who may feel coerced to give consent including offenders and participants in institutions such as care homes, educational or workplace settings where potential participants may feel obliged to consent to participate in order to conform with peers or service provider expectations (Cook \& Inglis, 2012; Edens et al., 2011; Goodman et al., 2011; Loyd, 2013). Potential participants, even when they understand study information, may ascribe additional meaning to their participation, or be motivated by a range of drivers not readily apparent to the researcher.

This study identified that at the time of consent, some parents were:

- Stressed and highly emotional,

- Finding it difficult to use or retain information about the study trial,

- Simultaneously subject to other measures of coercion,

- Feeling desperate to secure the speedy return of their child,

- Believing that by portraying an image of compliance, they could influence decisions about their child's future.

Thus, trial processes were contributing to delays in receiving a service and, in some cases, failing to secure fully informed consent. Despite these difficulties, there remains the ethical imperative to conduct trials of services; in this case, the trial aimed to contribute valuable information where there is currently scant evidence about how best to assess and intervene with maltreated children. Furthermore, there was equipoise between the two interventions 
and not enough of either to meet needs, such in the absence of knowledge about the relative benefits of the services some form of randomisation was an equitable method to allocate families to one or other intervention.

Some authors have argued that, in certain circumstances, randomisation to an intervention could occur prior to the informed consent of participants. For example, in the Zelen design, developed in the late 1970s, randomisation occurs and then individuals are offered the choice of accepting that intervention or not (Homer, 2002). More recent modifications of the Zelen design have been developed where all participants are enrolled traditionally in an observational study, but only those later randomised to an intervention arm are asked to participate in a further series of research assessments (Campbell, Peters, Grant, Quilty, \& Dieppe, 2005). Whilst this approach might be criticised for initially obscuring the full design of the study, researchers may argue that doing so is ethically justified as it avoids other potential problems.

Randomisation before consent has been used in the field of emergency medicine, but is rare elsewhere; for example it has been used in RCTs of interventions for head injury where the patient is unconscious at the time of entry to the study, but requires treatment without delay (CRASH, 2002). Researchers could justify such an approach in terms of,

- beneficence if the results of the trial were expected to produce future benefit,

- non-maleficence if delays to starting intervention whilst seeking consent would cause harm,

- equity if the approach facilitated equal access to the trial and interventions, and

- autonomy where it promoted circumstances that allowed potential participants more opportunity to use information and make a free choice.

In response to the issues identified in our nested qualitative study, we proposed that a followon multi-site definitive trial deploy a randomisation before consent protocol (see Figure 2).

$<$ Fig 2 about here >

This new model addresses many of the challenges identified above:

- Consent is sought at a time when parents are likely to be less stressed or emotional, 
- Parents are more likely to be able to use and retain information about the trial,

- Consent is sought after a service has been allocated and potentially initiated; this means that the recruiter can be clearer about specific content of the service,

- The sequence helps to separate the idea of participation in the trial from the idea of engaging with the service,

- Parents can take time to consider participation, without concern that this may delay intervention or decision-making.

Adopting a 'randomisation before consent' design such as the Zelen design has been shown to increase participation rates and reduce biases associated with the perceived desirability of the intervention over the control arm (Tu et al., 2004; Tyldum, 2012). However, an associated concern may be that the absence of a group who would only have been motivated by the chance of accessing a desired intervention could reduce overall participation and result in differently composed sample. Similarly, seeking consent after the initiation of intervention could result in different patterns of attrition, as no participants would drop out of the trial simply because they were disappointed about which the service they had been allocated to. The differential affects that randomisation before consent may have on participation and attrition need further exploration and we will evaluate how our modification influences this. We consider it likely that qualitative research will have a role by helping us understand potential participants' experiences and motivations.

\section{Conclusion}

Ensuring voluntary informed consent for research participation was challenging in the circumstances of this trial and yet ethical imperatives remain; careful research should be conducted to ascertain the efficacy of services and participants should have the opportunity to give consent. The nested qualitative study allowed us to identify problems with consent processes in this trial and to propose a solution. We consider that the new model addresses many difficulties and will be helpful when further testing this intervention.

All service areas must seek to ensure rigour and relevance of their evidence base. There have been assumptions that the challenges posed by complex human services such as social care, education, and justice will militate against the use of randomised trials. These interventions aim to make significant improvements to people's lives, and it seems that robust methods 
should have a key role in their development. Randomised controlled trials are possible in these settings, and randomisation before consent would be useful in circumstances where rapid response or intervention is important, where potential participants' understanding of information or decision-making might be temporarily impaired, and where there is genuine equipoise. We hope that this innovation will encourage similar studies and allow research to take place that might not previously have been possible.

\section{References}

Alderson, P., \& Morrow, V. (2004). Ethics, social research and consulting with children and young people (Revised ed.). Barkingside, Essex: Barnardo's.

Allmark, P. (1999). Should Zelen pre-randomised consent designs be used in some neonatal trials? Journal of Medical Ethics, 25(4), 325-329. Retrieved from http://www.scopus.com/inward/record.url?eid=2-s2.00032854629\&partnerlD=40\&md5=2f6dfcae955420a47390428302b04859

Allmark, P., \& Mason, S. (2006). Improving the quality of consent to randomised controlled trials by using continuous consent and clinician training in the consent process. Journal of Medical Ethics, 32(8), 439-443. doi:10.1136/jme.2005.013722

Appelbaum, P. S., Roth, L. H., \& Lidz, C. (1982). The therapeutic misconception: Informed consent in psychiatric research. International Journal of Law and Psychiatry, 5(3-4), 319-329. Retrieved from http://www.scopus.com/inward/record.url?eid=2-s2.00020390058\&partnerID=40\&md5=277560cf9917fc959437e015f79392c4

Behrendt, C., Gölz, T., Roesler, C., Bertz, H., \& Wünsch, A. (2011). What do our patients understand about their trial participation? Assessing patients' understanding of their informed consent consultation about randomised clinical trials. Journal of Medical Ethics, 37(2), 74-80. doi:10.1136/jme.2010.035485

BPS. (2014). Code of Human Research Ethics. Leicester: British Psychological Society.

Braun, V., \& Clarke, V. (2006). Using Thematic Analysis in Psychology. Qualitative Research and Psychology, 3, 77-101.

Broadhurst, K., Wastell, D., White, S., Hall, C., Peckover, S., Thompson, K., ... Davey, D. (2010). Performing 'initial assessment': Identifying the latent conditions for error at the front-door of local authority children's services. British Journal of Social Work, 40(2), 352-370.

Retrieved from http://www.scopus.com/inward/record.url?eid=2-s2.077949277601\&partnerID=40\&md5=5a6b784c8a01f3f03add8dfcc31629e0

BSA. (2002). Statement of Ethical Practice for the British Sociological Association. Durham: British Sociological Association.

Burgess, M. M. (2007). Proposing modesty for informed consent. Social Science and Medicine, 65(11), 2284-2295. doi:10.1016/j.socscimed.2007.08.006

Campbell, R., Peters, T., Grant, C., Quilty, B., \& Dieppe, P. (2005). Adapting the randomized consent (Zelen) design for trials of behavioural interventions for chronic disease: feasibility study. Journal of Health Services Research and Policy, 10(4), 220-225.

Carnochan, S., Moore, M., \& Austin, M. J. (2013). Achieving Timely Adoption. Journal of EvidenceBased Social Work, 10(3), 210-219. doi:10.1080/15433714.2013.788950 
Carpenter, W. T., Gold, J. M., Lahti, A. C., Queern, C. A., Conley, R. R., Bartko, J. J., . . Appelbaum, P. S. (2000). Decisional capacity for informed consent in schizophrenia research. Archives of General Psychiatry, 57(6), 533-538. Retrieved from http://www.scopus.com/inward/record.url?eid=2-s2.00342927486\&partnerlD=40\&md5=9b2ea97366ff1c17c530bb1cb889c938

Cook, T., \& Inglis, P. (2012). Participatory research with men with learning disability: Informed consent. Tizard Learning Disability Review, 17(2), 92-101. doi:10.1108/13595471211218875

Corrigan, O. (2003). Empty ethics: The problem with informed consent. Sociology of Health and IIIness, 25(7), 768-792. doi:10.1046/j.1467-9566.2003.00369.x

CRASH. (2002). The MRC CRASH Trial: study design, baseline data, and outcome in 1000 randomised patients in the pilot phase. Emergency Medicine Journal, 19(6), 510-514. Retrieved from http://www.ncbi.nlm.nih.gov/pmc/articles/PMC1756291/pdf/v019p00510.pdf

Crow, G., Wiles, R., Heath, S., \& Charles, V. (2006). Research ethics and data quality: The implications of informed consent. International Journal of Social Research Methodology: Theory and Practice, 9(2), 83-95. doi:10.1080/13645570600595231

David, M., Edwards, R., \& Alldred, P. (2001). Children and school-based research: 'Informed consent' or 'educated consent'? British Educational Research Journal, 27(3), 346-365. Retrieved from http://www.scopus.com/inward/record.url?eid=2-s2.00035374060\&partnerlD=40\&md5=bd30fb114bc0a7e161d4278555b8213c

Dombo, E. A., \& Bass, A. P. (2014). The Trials and Tribulations of a Practitioner-Researcher: Challenges and Lessons Learned through Testing a Feminist-Cognitive-Relational Social Work Model of Practice. Journal of Evidence-Based Social Work, 11(1-2), 43-57. Retrieved from http://www.scopus.com/inward/record.url?eid=2-s2.084891935399\&partnerID=40\&md5=65217b2f40faf45f8741a9d2e3ac23d7

Douglas, E. M., \& Serino, P. J. (2013). The extent of evidence-based information about child maltreatment fatalities in social science textbooks. Journal of Evidence-Based Social Work, 10(5), 447-454. Retrieved from http://www.scopus.com/inward/record.url?eid=2-s2.084890032827\&partnerID=40\&md5=b60c0a4b0469ad5031141db426ba0f3a

Dozier, M., Peloso, E., Lewis, E., Laurenceau, J. P., \& Levine, S. (2008). Effects of an attachmentbased intervention on the cortisol production of infants and toddlers in foster care. Development and Psychopathology, 20(3), 845-859. Retrieved from http://www.scopus.com/inward/record.url?eid=2-s2.048949116387\&partnerID=40\&md5=6978d9955bafd4ae1ab13ff899d04f9e

Edens, J. F., Epstein, M., Stiles, P. G., \& Poythress, N. G. (2011). Voluntary Consent in Correctional Settings: Do Offenders Feel Coerced to Participate in Research? Behavioral Sciences and the Law, 29(6), 771-795. doi:10.1002/bsl.1014

Edwards, P., Farrell, B., Lomas, G., Mashru, R., Ritchie, N., Roberts, I., .. Yates, D. (2002). The MRC CRASH Trial: Study design, baseline data, and outcome in 1000 randomised patients in the pilot phase. Emergency Medicine Journal, 19(6), 510-514. Retrieved from http://www.scopus.com/inward/record.url?eid=2-s2.00036850765\&partnerID=40\&md5=a59beeba8ddc18deb0c0cffbbcd96bec

Farmer, E. (2014). Improving reunification practice: pathways home, progress and outcomes for children returning from care to their parents. British Journal of Social Work, 44(2), 348-366. Retrieved from http://bjsw.oxfordjournals.org/

Fisher, J. A. (2013). Expanding the frame of "Voluntariness" in informed consent: Structural coercion and the power of social and economic context. Kennedy Institute of Ethics Journal, 23(4), 355-379. doi:10.1353/ken.2013.0018

Flewitt, R. (2005). Conducting research with young children: Some ethical considerations. Early Child Development and Care, 175(6), 553-565. doi:10.1080/03004430500131338 
Flory, J., \& Emanuel, E. (2004). Interventions to improve research participants' understanding in informed consent for research: A systematic review. Journal of the American Medical Association, 292(13), 1593-1601. doi:10.1001/jama.292.13.1593

Goodman, C., Baron, N. L., MacHen, I., Stevenson, E., Evans, C., Davies, S. L., \& lliffe, S. (2011). Culture, consent, costs and care homes: Enabling older people with dementia to participate in research. Aging and Mental Health, 15(4), 475-481. doi:10.1080/13607863.2010.543659

Graybeal, C. T. (2007). Evidence for the art of social work. Families in Society, 88(4), 513-523. Retrieved from http://www.scopus.com/inward/record.url?eid=2-s2.037649009365\&partnerID $=40 \&$ md5=175e562bac02fe895222e9f3edce92da

Hammersley, M. (2014). On ethical principles for social research. International Journal of Social Research Methodology. doi:http://dx.doi.org.10.1080/13645579.2014.924169

Homer, C. S. E. (2002). Using the Zelen design in randomized controlled trials: debates and controversies. Journal of Advanced Nursing, 38(2), 200-207.

Horwath, J. (2005). Identifying and assessing cases of child neglect: Learning from the Irish experience. Child and Family Social Work, 10(2), 99-110. Retrieved from http://www.scopus.com/inward/record.url?eid=2-s2.027944504266\&partnerID=40\&md5=c88bc3146de0055a4761a4244d326195

Joffe, S., Cook, E. F., Cleary, P. D., Clark, J. W., \& Weeks, J. C. (2001). Quality of informed consent in cancer clinical trials: A cross-sectional survey. Lancet, 358(9295), 1772-1777. doi:10.1016/S0140-6736(01)06805-2

Lieberman, A. F., Van Horn, P., \& Ippen, C. G. (2005). Toward evidence-based treatment: Childparent psychotherapy with preschoolers exposed to marital violence. Journal of the American Academy of Child and Adolescent Psychiatry, 44(12), 1241-1248.

Loyd, D. (2013). Obtaining consent from young people with autism to participate in research. British Journal of Learning Disabilities, 41(2), 133-140. doi:10.1111/j.1468-3156.2012.00734.x

Mason, S. A., \& Allmark, P. J. (2000). Obtaining informed consent to neonatal randomised controlled trials: Interviews with parents and clinicians in the Euricon study. Lancet, 356(9247), 20452051. doi:10.1016/S0140-6736(00)03401-2

Minnis, H., Bryce, G., Phin, L., \& Wilson, P. (2010). The "Spirit of New Orleans": Translating a model of intervention with maltreated children and their families for the Glasgow context. Clinical Child Psychology and Psychiatry, 15(4), 497-509.

Munro, E. R., \& Hardy, A. (2006). Placement stability: a review of the literature. Report to the DfES. Retrieved from Loughborough:

http://www.lboro.ac.uk/research/ccfr/Research/Outcomes\%20for\%20vulnerable\%20childre n/placementstability.htm

Newman, T., \& Roberts, H. (1997). Assessing social work effectiveness in child care practice: The contribution of randomized controlled trials. Child: Care, Health and Development, 23(4), 287-296. Retrieved from http://www.scopus.com/inward/record.url?eid=2-s2.00031178653\&partnerlD=40\&md5=3a7142f86240c6d6f0288f830dc58e32

Nishimura, A., Carey, J., Erwin, P. J., Tilburt, J. C., Murad, M. H., \& McCormick, J. B. (2013). Improving understanding in the research informed consent process: A systematic review of 54 interventions tested in randomized control trials. BMC Medical Ethics, 14(1). doi:10.1186/1472-6939-14-28

Nuremberg Code. (1947). The Nuremberg Code. Retrieved from https://history.nih.gov/research/downloads/nuremberg.pdf

O'Neill, O. (2003). Some limits of informed consent. Journal of Medical Ethics, 29(1), 4-7. doi:10.1136/jme.29.1.4

Parsons, S., Abbott, C., McKnight, L., \& Davies, C. (2015). High risk yet invisible: Conflicting narratives on social research involving children and young people, and the role of research ethics committees. British Educational Research Journal, 41(4), 709-729. doi:10.1002/berj.3160 
Potter, C. C., \& Klein-Rothschild, S. (2002). Getting home on time: Predicting timely permanence for young children. Child Welfare, 81(2), 123-150. Retrieved from

http://www.scopus.com/inward/record.url?eid=2-s2.00036517005\&partnerID=40\&md5=db9a6173e4e47484fd4e7ca1a153b557

Pritchett, R., Fitzpatrick, B., Watson, N., Cotmore, R., Wilson, P., Bryce, G., . . Minnis, H. (2013). A feasibility randomised controlled trial of the New Orleans Intervention for Infant Mental Health: A Study Protocol. The Scientific World Journal, Article ID 838042. Retrieved from http://www.hindawi.com/iournals/tswi/2013/838042/abs/

Regehr, C., Bogo, M., Shlonsky, A., \& LeBlanc, V. (2010). Confidence and professional judgment in assessing children's risk of abuse. Research on Social Work Practice, 20(6), 621-628.

Retrieved from http://www.scopus.com/inward/record.url?eid=2-s2.077958155014\&partnerID=40\&md5=59eb4381393316283f2ca18840c25d49

Reid, D., Ryan, T., \& Enderby, P. (2001). What does it mean to listen to people with dementia? Disability and Society, 16(3), 377-392. doi:10.1080/09687590120045941

Renold, E., Holland, S., Ross, N. J., \& Hillman, A. (2008). 'Becoming participant': Problematizing 'informed consent' in participatory research with young people in care. Qualitative Social Work, 7(4), 427-447. doi:10.1177/1473325008097139

Ritchie, J., \& Spencer, L. (1994). Qualitative data analysis for applied policy research Analysing Qualitative Data (pp. 173-194).

Roberts, H., Petticrew, M., Liabo, K., \& Macintyre, S. (2012). 'The Anglo-Saxon disease': A pilot study of the barriers to and facilitators of the use of randomised controlled trials of social programmes in an international context. Journal of Epidemiology and Community Health, 66(11), 1025-1029. doi:10.1136/jech-2011-200313

Schofield, G., Thoburn, J., Howell, D., \& Dickens, J. (2007). The search for stability and permanence: Modelling the pathways of long-stay looked after children. British Journal of Social Work, 37(4), 619-642. Retrieved from http://www.scopus.com/inward/record.url?eid=2-s2.051249154246\&partnerID=40\&md5=ec059a23d94d194ed7fe5a04a5127a92

Sinclair, I., Baker, C., Lee, J., \& Gibbs, I. (2007). The pursuit of permanence: a study of the English child care system. London: Jessica Kingsley.

Smyth, R. M. D., Jacoby, A., \& Elbourne, D. (2012). Deciding to join a perinatal randomised controlled trial: Experiences and views of pregnant women enroled in the Magpie Trial. Midwifery, 28, e538-e545. doi:doi:10.1016/j.midw.2011.08.006

Soydan, H. (2008). Applying randomized controlled trials and systematic reviews in social work research. Research on Social Work Practice, 18(4), 311-318. Retrieved from http://www.scopus.com/inward/record.url?eid=2-s2.044649158333\&partnerID=40\&md5=2eb04de6a35d0fd1c62e24e38ee0fee8

SRA. (2003). Ethical Guidelines. London: Social Research Association.

Stevens, M., Liabo, K., \& Roberts, H. (2007). A review of the research priorities of practitioners working with children in social care. Child and Family Social Work, 12(4), 295-305. Retrieved from http://www.scopus.com/inward/record.url?eid=2-s2.034848869179\&partnerID $=40 \& \mathrm{md5}=14374460 \mathrm{a} 80 \mathrm{~b} 4 \mathrm{~b} 8 \mathrm{a} 0 \mathrm{c} 1 \mathrm{a} 0 \mathrm{~d} 146 \mathrm{c} 37 \mathrm{cb} 57$

Thoburn, J., \& Courtney, M. E. (2011). A guide through the knowledge base on children in out-ofhome care. Journal of Children's Services, 6(4), 210-227. Retrieved from http://www.scopus.com/inward/record.url?eid=2-s2.084055199952\&partnerID=40\&md5=57aedb151b3b53adbd8c99f9f66e6e24

Tu, J. V., Willison, D. J., Silver, F. L., Fang, J., Richards, J. A., Laupacis, A., \& Kapral, M. K. (2004). Impracticability of Informed Consent in the Registry of the Canadian Stroke Network. New England Journal of Medicine, 350(14), 1414-1421. doi:10.1056/NEJMsa031697

Wade, J., Donovan, J. L., Athene Lane, J., Neal, D. E., \& Hamdy, F. C. (2009). It's not just what you say, it's also how you say it: Opening the 'black box' of informed consent appointments in 
randomised controlled trials. Social Science and Medicine, 68(11), 2018-2028.

doi:10.1016/j.socscimed.2009.02.023

Webber, M. (2014). From Ethnography to Randomized Controlled Trial: An Innovative Approach to Developing Complex Social Interventions. Journal of Evidence-Based Social Work, 11(1-2), 173-182. Retrieved from http://www.scopus.com/inward/record.url?eid=2-s2.084891922370\&partnerID $=40 \& \mathrm{md5}=\mathrm{d} 26862 \mathrm{ac} 363398 \mathrm{c} 3 \mathrm{~b} 8248616514 \mathrm{de} 27 \mathrm{a}$

Wiles, R., Crow, G., Charles, V., \& Heath, S. (2007). Informed consent and the research process: Following rules or striking balances? Sociological Research Online, 12(2). Retrieved from http://www.scopus.com/inward/record.url?eid=2-s2.040149090153\&partnerlD=40\&md5=b9f6a07f3e4224f6c196f3d4aed961f1

Williams, N. J., \& Sherr, M. E. (2013). Oh How I Try to Use Evidence in my Social Work Practice: Efforts, Successes, Frustrations, and Questions. Journal of Evidence-Based Social Work, 10(2), 100-110. Retrieved from http://www.scopus.com/inward/record.url?eid=2-s2.084876327701\&partnerID=40\&md5=21f57928daad30f273cc0d4359e5ad23

WMA. (2013). The World Medical Association Declaration of Helsinki (7th Revision) - Ethical Principles for Medical Research Involving Human Subjects. Retrieved from http://www.wma.net/en/30publications/10policies/b3/

Wolbransky, M., Goldstein, N. E. S., Giallella, C., \& Heilbrun, K. (2013). Collecting informed consent with juvenile justice populations: Issues and implications for research. Behavioral Sciences and the Law, 31(4), 457-476. doi:10.1002/bsl.2068

Zeanah, C. H., Gunnar, M. R., McCall, R. B., Kreppner, J. M., \& Fox, N. A. (2011). Sensitive Periods. Monographs of the Society for Research in Child Development, 76(4), 147-162.

Zeanah, C. H., Larrieu, J. A., Heller, S. S., Valliere, J., Hinshaw-Fuselier, S., Aoki, Y., \& Drilling, M. (2001). Evaluation of a preventive intervention for maltreated infants and toddlers in foster care. Journal of the American Academy of Child and Adolescent Psychiatry, 40(2), 214-221.

Zeira, A., Canali, C., Vecchiato, T., Jergeby, U., Thoburn, J., \& Neve, E. (2008). Evidence-based social work practice with children and families: A cross national perspective. European Journal of Social Work, 11(1), 57-72. Retrieved from http://www.scopus.com/inward/record.url?eid=2-s2.040749133405\&partnerID=40\&md5=37ecd762b57f2a74b14331cfd767c8e0 


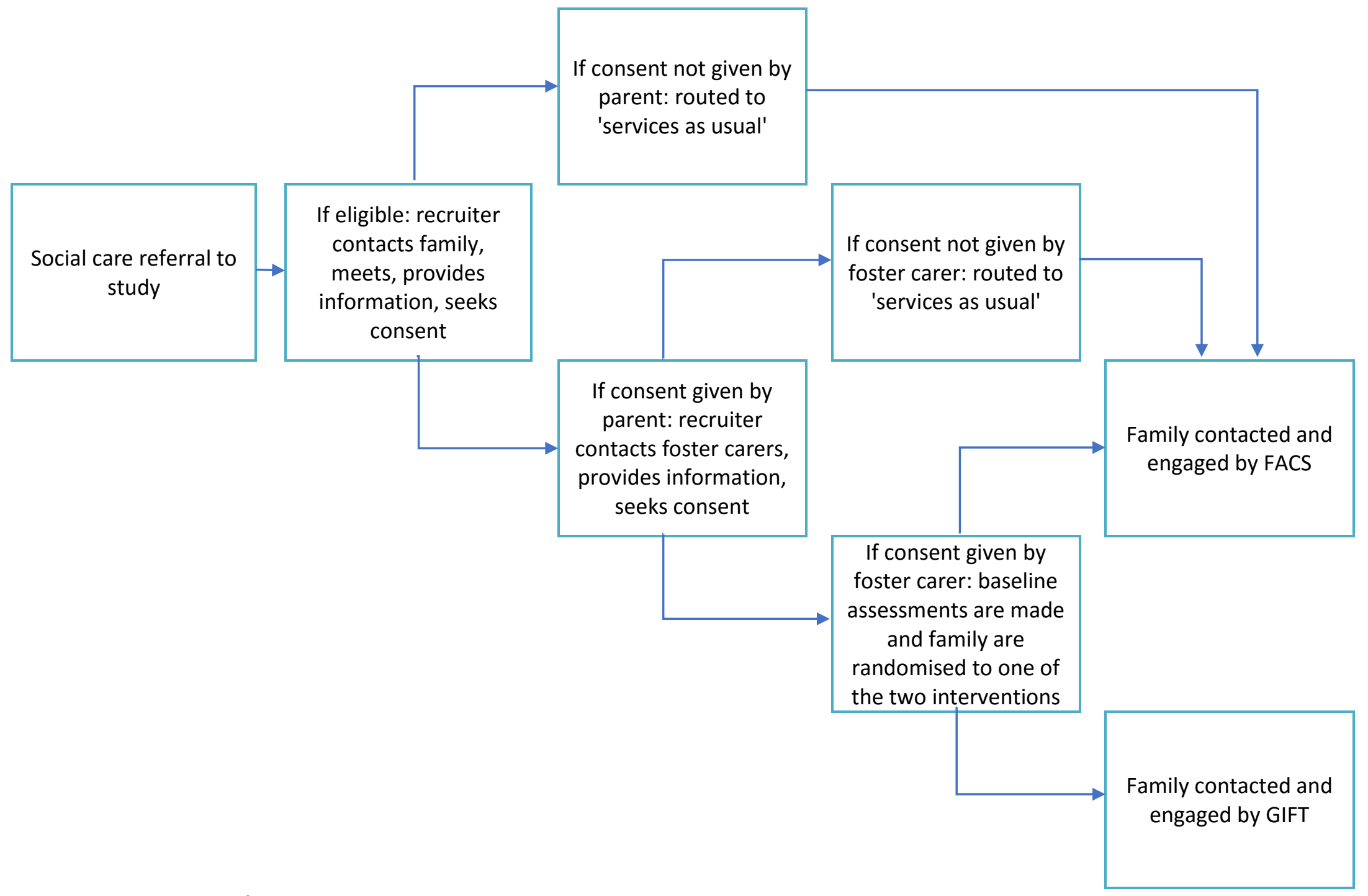

Figure 1: Summary of original recruitment process 


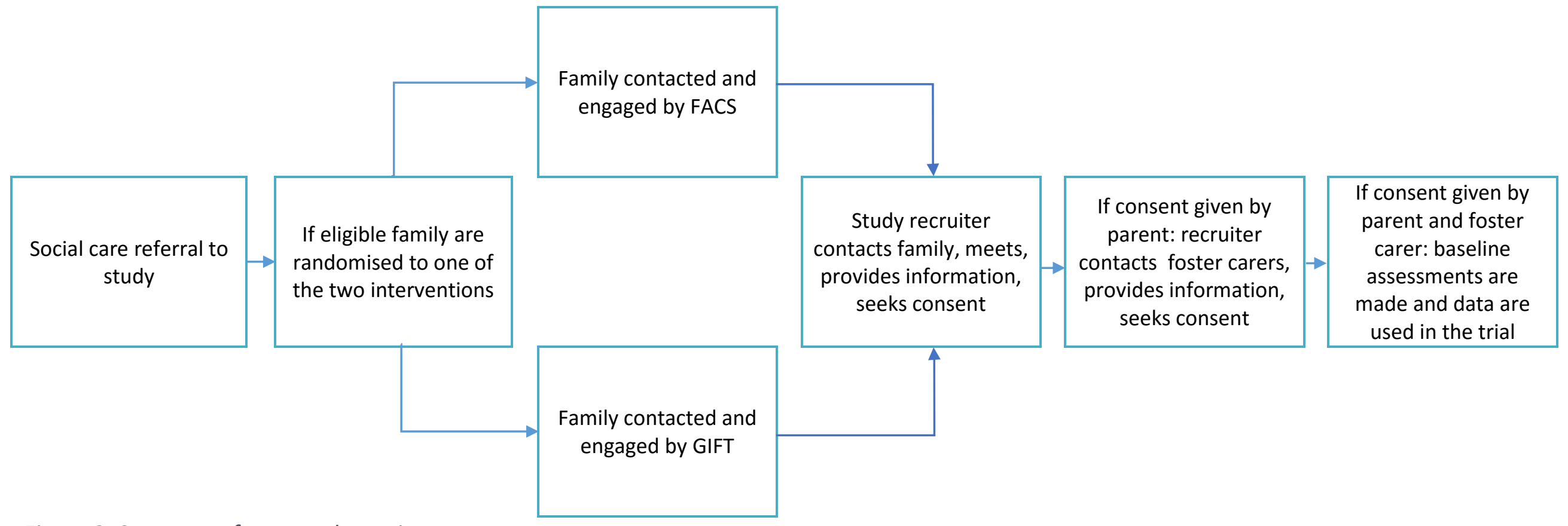

Figure 2: Summary of proposed recruitment process 